\title{
Identification of genomic regions that contribute to wet carcass syndrome in sheep
}

\author{
L. van der Westhuizen ${ }^{1,2}$, M.D. MacNeil ${ }^{1,2,3}$, M.M. Scholtz ${ }^{\# 1,2}$ \& F.W.C. Neser ${ }^{2}$ \\ ${ }^{1}$ ARC-Animal Production, Private Bag X2, 0062, Irene, South Africa \\ ${ }^{2}$ Department of Animal, Wildlife and Grassland Sciences, UFS, P.O. Box 339, Bloemfontein, 9300, South Africa \\ ${ }^{3}$ Delta G, 145 Ice Cave Road, MT 59301, Miles City, USA
}

(Received 5 February 2019; Accepted 28 August 2019; First published online 1 October 2019)

Copyright resides with the authors in terms of the Creative Commons Attribution 4.0 South African Licence.
See: http://creativecommons.org/licenses/by/4.0/za
Condition of use: The user may copy, distribute, transmit and adapt the work, but must recognise the authors and the South African
Journal of Animal Science.

\begin{abstract}
Wet carcass syndrome (WCS), which is observed predominantly in sheep, affects carcass quality negatively. After slaughter the carcass appears to be 'wet' with a subcutaneous accumulation of watery fluid. Not all animals in a contemporary group are afflicted, and experimental attempts to induce WCS have been unsuccessful. The reported prevalence of WCS in Dorper and Dorper crosses gave rise to the hypothesis that it may have a genetic basis. Therefore, the primary objective of this investigation was to test this hypothesis using a high-density SNP assay to search loci that may predispose sheep to WCS. Muscle samples from 43 afflicted and 41 unafflicted sheep were collected from slaughterhouses in the province of Northern Cape, South Africa, and in southern Namibia. Tests against candidate genes proved uninformative, as did runs of homozygosity. Potential associations between WCS and an autosomal genetic marker were investigated further in a case-control genome-wide association study. Separate analyses for each sex were motivated because single nucleotide polymorphisms (SNPs) on the $X$ chromosome suggested quantitative trait loci. These analyses revealed significant associations between SNP and WCS in males, but not in females. Three SNPs that reached genome-wide significance in males are in strong linkage disequilibrium with the Duchenne muscular dystrophy, 5-hydroxytryptamine receptor $2 \mathrm{C}$, and Teneurin transmembrane protein 1 genes. These genes are identified as positional candidate genes, and the Duchenne muscular dystrophy, 5-hydroxytryptamine receptor $2 \mathrm{C}$ genes have biological effects that have been documented in other species, making them plausible functional candidate genes for WCS in sheep.
\end{abstract}

Keywords: association analysis, Dorper, sheep carcass, single nucleotide polymorphisms, X chromosome

${ }^{\#}$ Corresponding author: GScholtz@arc.agric.za

\section{Introduction}

Wet carcass syndrome (WCS) is a condition that is found predominantly in sheep, which affects the quality of their carcasses negatively. Although WCS has been the subject of research since 1981 (Brock et al., 1983; Hattingh et al., 1983), its aetiology remains undetermined. The first incidence of WCS was recorded in January of 1981 at Chambor abattoir in Krugersdorp, Gauteng, South Africa (Jansen, 1991). It is most frequently observed in Dorper and crosses of Dorper with indigenous and locally developed breeds of South Africa and Namibia (Brock et al., 1983; Webb \& Van Niekerk, 2011). During the pre-slaughter period the animal appears to be clinically normal. However, after slaughter and removal of the skin the carcass appears to be 'wet' (Hattingh et al., 1983). As shown in Figure 1, the condition can be described as a subcutaneous accumulation of watery fluid (Brock et al., 1983). The areas of the carcass that are most affected are the brisket, flanks, hindquarters, sides, and back (Hattingh et al., 1983; Brock et al., 1983). The watery fluid is also found in the intramuscular connective tissue layers of the flank and subscapular area. Afflicted carcasses do not dry off with overnight cooling (Joubert et al., 1985), pose difficulties during meat processing and the meat has a diminished shelf life (Joubert et al., 1985). Therefore, these carcasses are deemed unacceptable, and are condemned by the meat inspectors. In South Africa, economic losses that stem from WCS were approximately R27 million in 2010 (Webb \& Van Niekerk, 2011; Le Roux, 2012).

Not all animals in a flock that are sent to slaughter at one time are afflicted, and inducing the condition 
experimentally has proved unsuccessful. To date, many physiological and nutritional factors, as well as environmental agents and management systems, have been postulated and evaluated without a cause for the condition having been identified (reviewed by Van der Westhuizen, 2018). Despite apparent overrepresentation of WCS in Dorper, which may indicate genetic causation, there have been no prior investigations of a potential genetic predisposition to WCS (Van der Westhuizen, 2018). Furthermore, pedigree data are currently unavailable with which to perform analyses that would assist in estimating heritability or the mode of transmission of WCS.

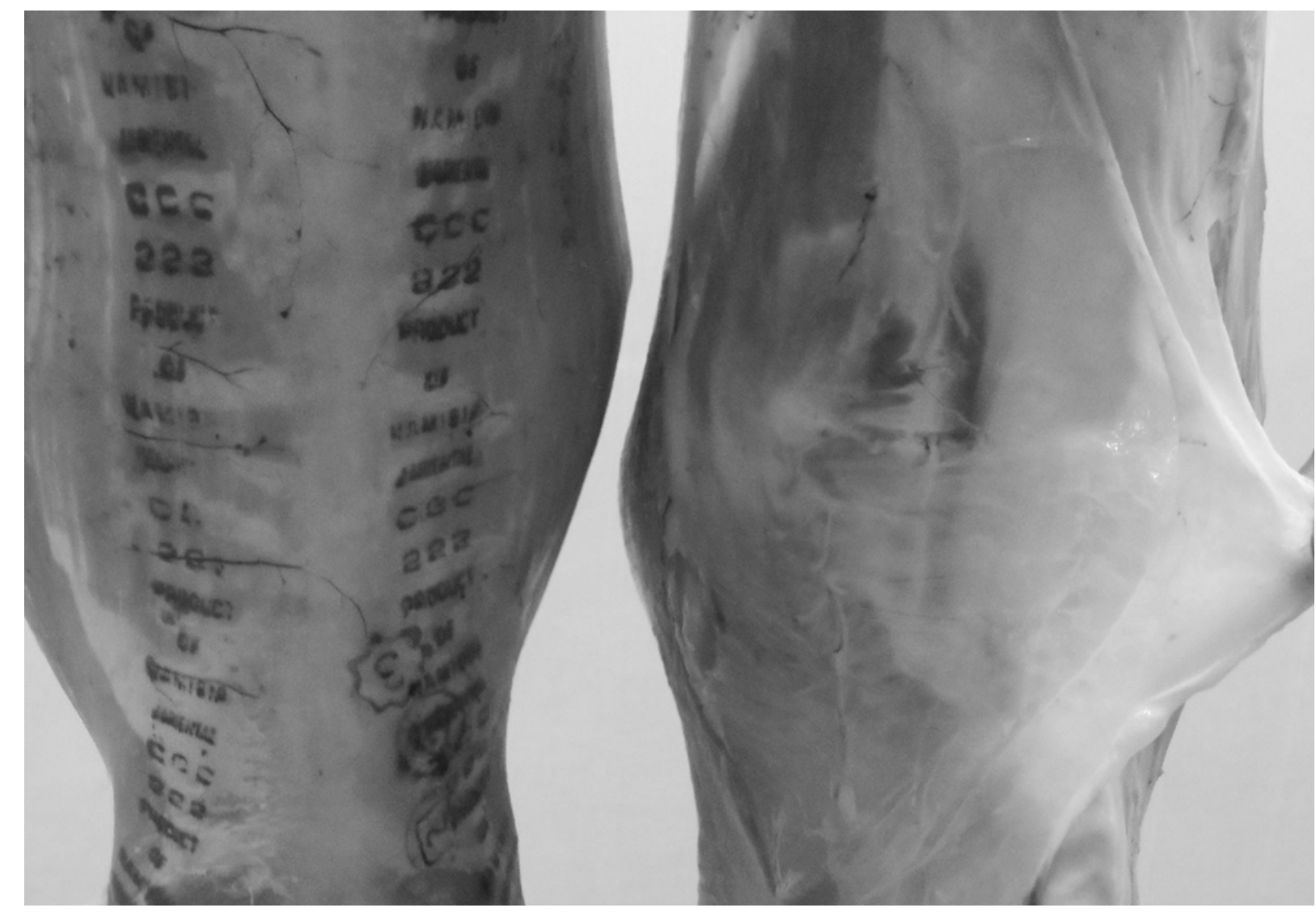

Figure 1 Carcass from a sheep that was not afflicted with wet carcass syndrome (left) compared to the carcass from an afflicted sheep.

The study of genetic diseases falls into two categories, that is, population-based studies and familybased studies. Population-based studies generally use a case-control study design to identify candidate gene regions (Miyagawa et al., 2008). In early forms of population-based studies, candidate gene studies relied on the similarity of phenotypes across species and previous identification of a causative locus in a species other than the one that was currently under investigation (Harhay \& Keele, 2003). From the early 2000s to date, genome-wide association studies (GWAS) using high-density SNPs have become the conventional method of identifying statistically significant loci that underlie common and complex diseases (Hirschhorn \& Daly, 2005; Miyagawa et al., 2008; Clarke et al., 2011).

The GWAS approach has been used successfully to identify quantitative trait loci (QTL) and putative candidate genes in wool (Wang et al., 2014), meat (Zhang et al., 2013), milk production (García-Gámez et al., 2012), bodyweight (Al-Mamun et al., 2015), body size (Kominakis et al., 2017), rickets (Zhao et al., 2011), polyceraty (Greyvenstein et al., 2016), horns (Johnston et al., 2011), litter size (Demars et al., 2013), and chondrodysplasia (Zhao et al., 2012) in sheep. For a GWAS, populations consisting of afflicted and unafflicted individuals are compared using the frequencies of alleles or genotypes, that is, a case and control study. If a higher frequency of a SNP variant exists in the afflicted group (afflicted individuals with a specific phenotype), or is statistically more common in the afflicted group, the alleles or genotypes are regarded as being associated with the disease (Hirschhorn et al., 2002). SNPs, which are spaced approximately evenly across the genome, may be tested independently for an association with a specific phenotype (Balding, 
2006; Kemper et al., 2012).

Two conditions that are phenotypically similar to WCS are porcine stress syndrome (PSS), which results in pale, soft, and exudative (PSE) meat (Ludvigsen, 1957; Wismer-Pedersen, 1959), and reddish, soft, and exudative meat (RSE) (Le Roy et al., 1990). Both PSE and RSE become apparent after slaughter and result from mutations at single loci. Porcine stress syndrome, which results in PSE pork, is caused by a single autosomal recessive mutation in the ryanodine receptor 1 (RYR1) gene (Hall et al., 1980; Fujii et al. 1991; MacLennan \& Phillips, 1992). In the porcine species, this gene is located on chromosome 6 (SSC6) (Harbitz et al., 1990) (map position on Sus scrofa Sscrofa11.1 is 47,339,759-47,458,457 (Sayers et al., $2019 a, b)$. This mutation affects the calcium ion release channel of the sarcoplasmic reticulum. The channel opens properly, but closing is inhibited (Endo et al., 1983; O'Brien, 1986; Fill et al., 1990). Therefore, the mutation, combined with pre-slaughter stress, causes rapid glycolysis early post slaughter where the $\mathrm{pH}$ of the carcass meat is lower than six $(<6)$ at 45 minutes post slaughter (Wismer-Pedersen, 1959; Aalhus et al., 1998; Schaefer et al., 2001), causing PSE meat. There have been reports of PSE meat in other species, including cattle (Aalhus et al., 1998), ostriches (Van Schalkwyk et al., 2000), turkeys (McCurdy et al., 1996; McKee et al., 1998; Owens et al., 2000), and chickens (Swatland, 2008). Adzitey \& Nurul (2011) stated that PSE meat can be found in all species, with its manifestation being dependent on pre-slaughter handling.

The RSE condition was proposed by Le Roy et al. (1990) and Warner et al. (1997) to result from a mutation in the Rendement Napole (RN $N^{-}$or PRKAG3) gene. Warner et al. (1997) also proposed that the low $\mathrm{pH}$ and high glycogen content in the muscle results in low processing yields, which are typical characteristics in the presence of the $R N^{-}$genotype. The $R N^{-}$gene has an autosomal dominant inheritance pattern (Le Roy et al., 1990) and is located between markers SW120 and SW936 on chromosome 15 (SSC15) in the porcine genome (Milan et al., 1995; Mariani et al., 1996). A total of five causal substitution mutations within the PRKAG3 gene have been identified, and include I199V, R200Q, T30N, L53P, and G52S (Milan et al., 2000; Ciobanu et al., 2001; Chen et al., 2008). The PRKAG3 gene mechanism encodes for a muscle isoform of the regulatory $\mathrm{Y}$-subunit, which forms part of the adenosine monophosphate (AMP) activated protein kinase (AMPK). The enzyme AMPK is essential to the regulation of energy metabolism. During the postslaughter period, glycogen is altered to lactic acid. The presence of lactic acid (Lundström et al., 1996; Enfält et al., 1997) causes a low ultimate pH (Miller et al., 2000; Lindahl et al., 2004; Škrlep et al., 2010). Therefore, RSE or acid meat exhibits a high drip loss and has low water-holding capacity (Le Roy et al., 1996; Le Roy et al., 2000; Škrlep et al., 2010).

Given this background, the overarching goal of this research was to determine whether there is a genetic predisposition for WCS. Thus, the specific objectives were i) to map sequences for porcine RYR1 and PRKAG3 onto the ovine genome and test co-located SNP variants for association with WCS; ii) to detect autosomal loci that showed consistent homozygosity in all afflicted sheep; iii) to identify genomic regions that harboured genetic variants that predispose sheep to WCS; and iv) to postulate candidate genes in any identified regions based on functional similarities that have been identified in the annotation of genomes of other species.

\section{Materials and Methods}

Muscle samples from 43 afflicted and 41 unafflicted sheep carcasses were collected from three abattoirs in the province of Northern Cape, South Africa, and in southern Namibia. Abattoirs in South Africa were selected from those in the geographical areas in which WCS had had a relatively high prevalence in the past. At each abattoir, personnel were instructed to select afflicted and unafflicted carcasses as pairs from the same cohort. This would minimize the risk of false positive associations (Type I error) due to selection biases and population stratification (Cardon \& Palmer, 2003; Hirschhorn \& Daly, 2005; Turner et al., 2011). Sex of the animals was not recorded at the abattoirs. Sex was therefore assigned to animals based on mean heterozygosity rates using the --check-sex command of PLINK (Purcell et al., 2007). In examining the genotypes from the $X$ chromosome, an animal was assumed to be a female when the inbreeding coefficient $(F)$ was less than $0.2(F \leq 0.2)$ and a male when $F$ was greater than $0.8(F \geq 0.8)$ (Anderson et al., 2010; Turner et al., 2011; Alonso et al., 2015).

Genomic DNA was extracted from muscle samples using the First-DNA all tissue extraction kit (GENIAL GmbH, Troisdorf, Germany) following the manufacturer's instructions, with minor modifications that best suited muscle samples. Roughly chopped muscle was placed in a 1.5 millilitre $(\mathrm{mL})$ reaction vessel with 500 microlitres $(\mu \mathrm{L})$ lysis buffer $1,50 \mu \mathrm{L}$ lysis buffer 2 , and $5 \mu \mathrm{L}$ Proteinase $\mathrm{K}$, and incubated for $90 \mathrm{~min}$ at $65^{\circ} \mathrm{C}$. Centrifugation occurred for $10 \mathrm{~min}$ at 12000 revolutions per minute (rpm) from which $500 \mu \mathrm{L}$ supernatant was transferred to a fresh reaction vessel. A total of $375 \mu \mathrm{L}$ of lysis buffer 3 was added, and then vortexed for 20 seconds. The samples were chilled in a freezer for $5 \mathrm{~min}$ and again centrifuged for $10 \mathrm{~min}$ at 13000 $\mathrm{rpm}$. A total of $800 \mu \mathrm{L}$ supernatant was transferred into a fresh reaction vessel. Then $640 \mu \mathrm{L}$ isopropanol was added and mixed carefully. 
To obtain a DNA pellet the samples were centrifuged for $15 \mathrm{~min}$ at $13000 \mathrm{rpm}$. The supernatant was removed, and the pellet washed with $300 \mu \mathrm{L}$ chilled $70 \%$ ethanol $(\mathrm{EtOH})$ and centrifuged for 5 min at 13000 $\mathrm{rpm}$. The pellet was air dried overnight, dissolved in $50 \mu \mathrm{L}$ double distilled water $\left(\mathrm{ddH}_{2} \mathrm{O}\right)$, and stored at -80 ${ }^{\circ} \mathrm{C}$. Nucleic acid (DNA) concentration was determined using a NanoDrop 2000 spectrometer (Thermo Fisher Scientific, Waltham, Massachusetts, USA). A total of $1 \mu \mathrm{L}$ of DNA was used for each measurement. DNA extraction products were also run on a gel electrophoresis system (Bio-Rad, Hercules, California, USA). A total of $3 \mu \mathrm{L}$ DNA was added to $3 \mu \mathrm{L}$ of loading dye, mixed and loaded into the gel (1\% 50x Tris/Acetic Acid/EDTA (TAE) and $0.003 \%$ ethidium bromide (EtBr)). The gel ran for 20 min at 100 Volts (V) and was then UV visualized with the Bio-Rad Molecular Imager® Gel DocTM XR+ System controlled by Image Lab software. The final quantity of DNA and its purity was determined using the Qubit 3.0 fluorometer (Invitrogen, Thermo Fisher Scientific, Carlsbad, California, USA) following the manufacturer's instructions.

All DNA samples were genotyped at the Agricultural Research Council Biotechnology Platform, using the Ovine Infinium ${ }^{\circledR}$ HD SNP BeadChip (Illumina Inc., San Diego, California, USA). The BeadChip features 685734 SNPs that are approximately equally distributed throughout the domestic sheep (Ovis aries) genome on 26 autosomes and the X chromosome (Kijas et al., 2014). Illumina GenomeStudio Genotyping Module Software v2.0 (Illumina Inc., San Diego, California, USA) was used to convert raw signal intensities into genotype calls.

PLINK v1.07 (Purcell et al., 2007) was used for individual and SNP quality control (QC) measures. The missing genotype rate per individual was calculated using the --mind command and individuals with call rate $<90 \%$ were excluded following Zhang et al. (2013) and Hao et al. (2017). Individuals with observed homozygosity (calculated using --het) outside the range $\mu \pm 3 S D$ were deleted from the data. Pairwise identity-by-descent (IBD) estimation (--genome, IBD > 0.1875) was used to identify individuals with shared ancestry and potential duplicate samples. Markers without a known chromosomal position on the ovine genome sequence (Ovis aries Oar_v4.0) were also excluded from further analyses, as were markers with call rates $(--$ geno $)<0.90$ and minor allele frequency (MAF) $(--m a f)<0.01$. Sex was assigned to animals based on the presence $(F \leq 0.2=$ female) or absence $(F \geq 0.8=$ male $)$ of heterozygosity of the $X$ chromosome. A pruned SNP dataset (227 768 SNPs) by means of linkage disequilibrium (--indep-pairwise 505 0.5) was used to conduct principal component analysis using the SNPRelate and gdsfmt packages (Zheng et al., 2012) in R (R Core Team, 2013). Only two samples were removed because of population stratification.

After editing, 69 individuals (33 afflicted and 36 unafflicted) and 552490 SNPs remained for analyses. To identify loci that were associated with the WCS phenotype, a GWAS applicable to a case-control study design was implemented along with Fisher's exact test (--fisher) in PLINK v1.07 (Purcell et al., 2007). Fisher's exact test avoids problems of approximation that are exacerbated by small sample sizes (Kim, 2017). This test compares genotype frequencies between afflicted (case) and unafflicted (control) samples to associate the WCS phenotype with SNP genotype. The classical Bonferroni correction of the $P$-values was used to provide a critical value for significance testing at $P=0.05$.

The qqman- (Turner, 2014) and RColorBrewer packages in R (R Core Team, 2013) were used to create and visualize the GWAS results by means of Manhattan- and quantile-quantile (Q-Q) plots. Gene and SNP annotation were completed by using NCBI Ovis aries_v4.0 (Sayer et al., 2019a,b) and Ensembl (Aken et al., 2016) using ovine genome assembly 3.1.

\section{Results and Discussion}

Using BLAST (Altschul et al., 1997), homologs of the functional candidate genes PRKAG3 and RYR1 were positioned at 219,781,028-219,787,070 on chromosome 2 (OAR2) and 47,426,122-47,552,121 on chromosome 14 (OAR14) within the Ovis aries genome, respectively (Figure 2). Three SNPs on the Ovine Infinium ${ }^{\circledR}$ HD SNP BeadChip were located in the PRKAG3 gene on OAR2, and 25 SNP were located in the RYR1 gene on OAR14 (Van der Westhuizen, 2018). Two additional SNP near the upstream promoter regions were also identified. Logistic regression of the presence or absence of WCS on each SNP genotype indicated that for PRKAG3, oar3_OAR2_219782879 had the smallest $P$-value (0.19) and for RYR1, oar3_OAR14_47532583 had the smallest $\bar{P}$-value (0.01). However, no other SNP within RYR1 approached significance in affecting the occurrence of WCS and it was concluded that although PSS and RSE are phenotypically similar to WCS, the current results do not support the hypothesis that mutations in RYR1 or PRKAG3 cause WCS. 


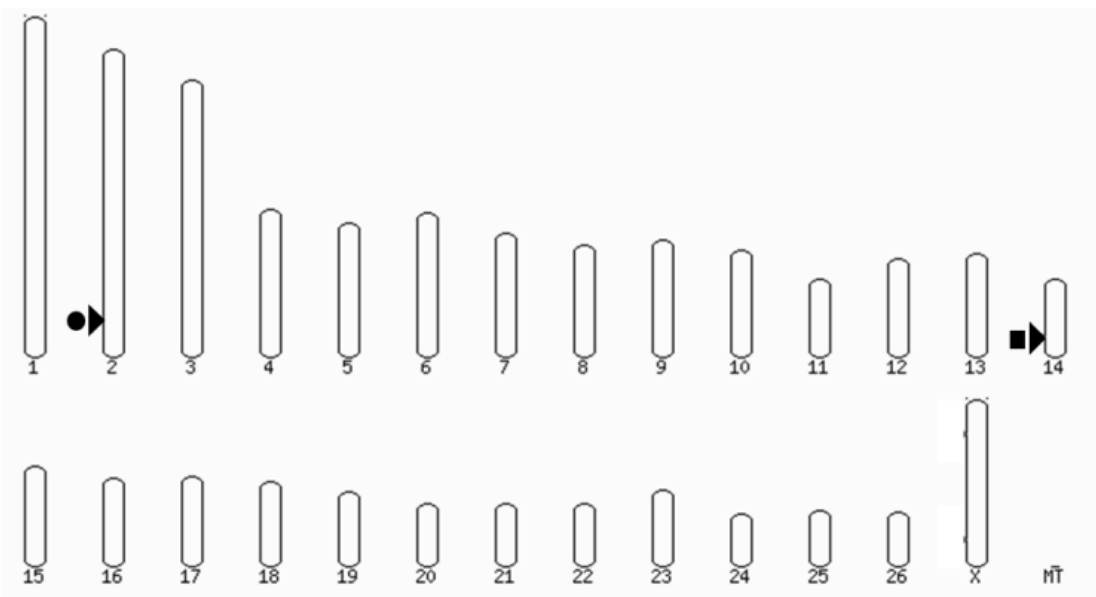

Figure 2 Position of PRKAG3 on chrosome 2 and RYR1 on chromosome 14 in the ovine genome

To determine whether there is an autosomal region that harbours a causative mutation(s) that affect WCS, the genomes of all afflicted animals $(n=33)$ were scanned for common runs of homozygosity. A total of 527694 SNP loci on 26 autosomes were used in this evaluation. The number of identified homozygous segments in all afflicted animals ranged from 47 to 140 , with a mean of $88.06 \pm 3.97$. The segment sizes ranged from $2344.03 \mathrm{~kb}$ to $3625.414 \mathrm{~kb}$ with a mean of $2856.54 \pm 238.71 \mathrm{~kb}$. No homozygous segments were identified as overlapping on any of the autosomes in all of the 33 afflicted animals. The greatest number of afflicted animals that shared an overlapping homozygous segment was 24 . This consensus region was initiated with oar3_OAR3_106048097 and was terminated with oar3_OAR3_107139271. Thus, these results are interpreted to indicate the absence of a recessive mutation on any of the autosomes that harbour the causal locus for WCS and support the interpretation that RYR1 and PRKAG3 are not causal genes.

A similar analysis was conducted with the SNP genotypes of afflicted females $(n=14)$ to search for runs of homozygosity on OARX. A total of 25001 SNPs were available for this analysis. The number of identified homozygous segments in all afflicted animals ranged from 4 to 13 with a mean of $8.14 \pm 0.78$ and the average segment sizes ranged from $1968.27 \mathrm{~kb}$ to $3757.46 \mathrm{~kb}$, with a mean of $2538.51 \pm 123.45 \mathrm{~kb}$. Two loci were found to have overlapping homozygous segments in 13 of the 14 afflicted females. The first consensus region was initiated with oar3_OARX_73198255 and was terminated with oar3_OARX_73994257. This region was also found to be homozygous in 13 unafflicted females. The second consensus region was initiated with oar3_OARX_56609654 and was terminated with oar3_OARX_56624555. This region was also found to be homozygous in 12 of the unafflicted females. The lack of any overlapping runs of homozygosity provided plausible evidence to support the notion that WCS is not inherited as a simple recessive condition, unless there had been an error in genotyping or an individual had been mistakenly identified as being afflicted.

The initial GWAS included data from 19 afflicted and 19 unafflicted males and 14 afflicted and 17 unafflicted females (Figure 3). It detected 14 SNPs that were suggestively associated $\left(P \leq 1 \cdot 10^{-5}\right)$ with WCS (Table 1). Five of the SNPs were located on chromosome 1 (OAR1), chromosome 4 (OAR4), chromosome 8 (OAR8), chromosome 11 (OAR11), and chromosome 24 (OAR24), and nine SNPs were located on the $X$ chromosome (OARX). For the autosomal loci that were associated with WCS, no other nearby loci were similarly associated and these associations could result from genotyping artefacts or chance as a consequence of small sample size. The $X$ chromosome was clearly distinguished from the autosomes by the presence of several SNPs that formed an apparent QTL peak. Because X-linked variants may have different effects between males and females (Dobyns et al., 2004) there was adequate incentive to conduct a separate GWAS analysis for each sex. Unfortunately, the power of these separate analyses was compromised owing to reduced allelic sample size (Gottipati et al., 2011).

In the data from males, two SNPs on OARX were found to reach the genome-wide significance threshold relating to WCS (Figure 4). The loci oar3_OARX_29903534 ( $\left.P=4.56 \cdot 10^{-8}\right)$ and oar3_OARX_113973214 $\left(P=6.16 \cdot 10^{-8}\right)$ are located in the region of OARX, which is not pseudo-autosomal (Das et al., 2009). These loci are separated by approximately 83 megabase pairs (Mbp), where OARX_113973214 is approximately 11 Mbp downstream from oar3_OARX_102819706 and oar3_OARX_102834391. However, the analysis of the data from females failed to detect suggestive associations with WCS. 
Table 1 Loci on the $X$ chromosome and autosomes showing suggestive association with wet carcass syndrome when both sexes were used in the genome-wide association analysis

\begin{tabular}{|c|c|c|c|c|c|}
\hline SNP & Chr & RefSNP ID & Locus & $P$-value & Related genes ${ }^{1}$ \\
\hline OAR1_245730132.1 & 1 & rs414552741 & 227901188 & $5.61 \cdot 10^{-7}$ & intergenic \\
\hline OAR3_OAR4_44743238 & 4 & rs424871551 & 44720173 & $2.09 \cdot 10^{-6}$ & $R E L N$ \\
\hline OAR8_45760589.1 & 8 & rs403004733 & 42572637 & $5.74 \cdot 10^{-6}$ & Intergenic \\
\hline OAR3_OAR11_35812793 & 11 & rs406416952 & 35763513 & $4.56 \cdot 10^{-6}$ & Intergenic \\
\hline OAR3_OAR24_9440581 & 24 & rs402465452 & 9442405 & $5.40 \cdot 10^{-6}$ & NUBP1 \\
\hline OAR3_OARX_29903534 & $x$ & rs403503557 & 29903034 & $4.56 \cdot 10^{-8}$ & Intergenic \\
\hline OAR3_OARX_35953513 & $x$ & rs400747921 & 35932202 & $3.59 \cdot 10^{-6}$ & Intergenic \\
\hline OAR3_OARX_98985496 & $x$ & rs416506282 & 98824617 & $6.43 \cdot 10^{-6}$ & TMEM255A \\
\hline OAR3_OARX_102811671 & $x$ & rs413794928 & 102644717 & $4.87 \cdot 10^{-6}$ & TENM1 \\
\hline OAR3_OARX_102817582 & $x$ & rs422039869 & 102650628 & $4.87 \cdot 10^{-6}$ & TENM1 \\
\hline OAR3_OARX_102819706 & $x$ & rs426965083 & 102652752 & $9.40 \cdot 10^{-6}$ & TENM1 \\
\hline OAR3_OARX_102834391 & $x$ & rs416468050 & 102667437 & $4.24 \cdot 10^{-6}$ & TENM1 \\
\hline OAR3_OARX_113973214 & $x$ & rs399985763 & 113751984 & $4.67 \cdot 10^{-7}$ & Intergenic \\
\hline OAR3_OARX_113988383 & $x$ & rs414187600 & 113767153 & $2.43 \cdot 10^{-6}$ & Intergenic \\
\hline
\end{tabular}

SNP: name of the single nucleotide polymorhism; Chr: chromosome; refSNP ID: SNP identification (Oar_v4.0); Locus: base pair position on Opr_v4.0; $P$-value: $P$-values from Fisher's exact test

${ }^{1}$ RELN: Reelin; NUBP1: nucleotide binding protein 1; TMEM255A: transmembrane protein 255A; TENM1: Teneurin transmembrane protein 1 ; Intergenic: regions in which no genes have been annotated

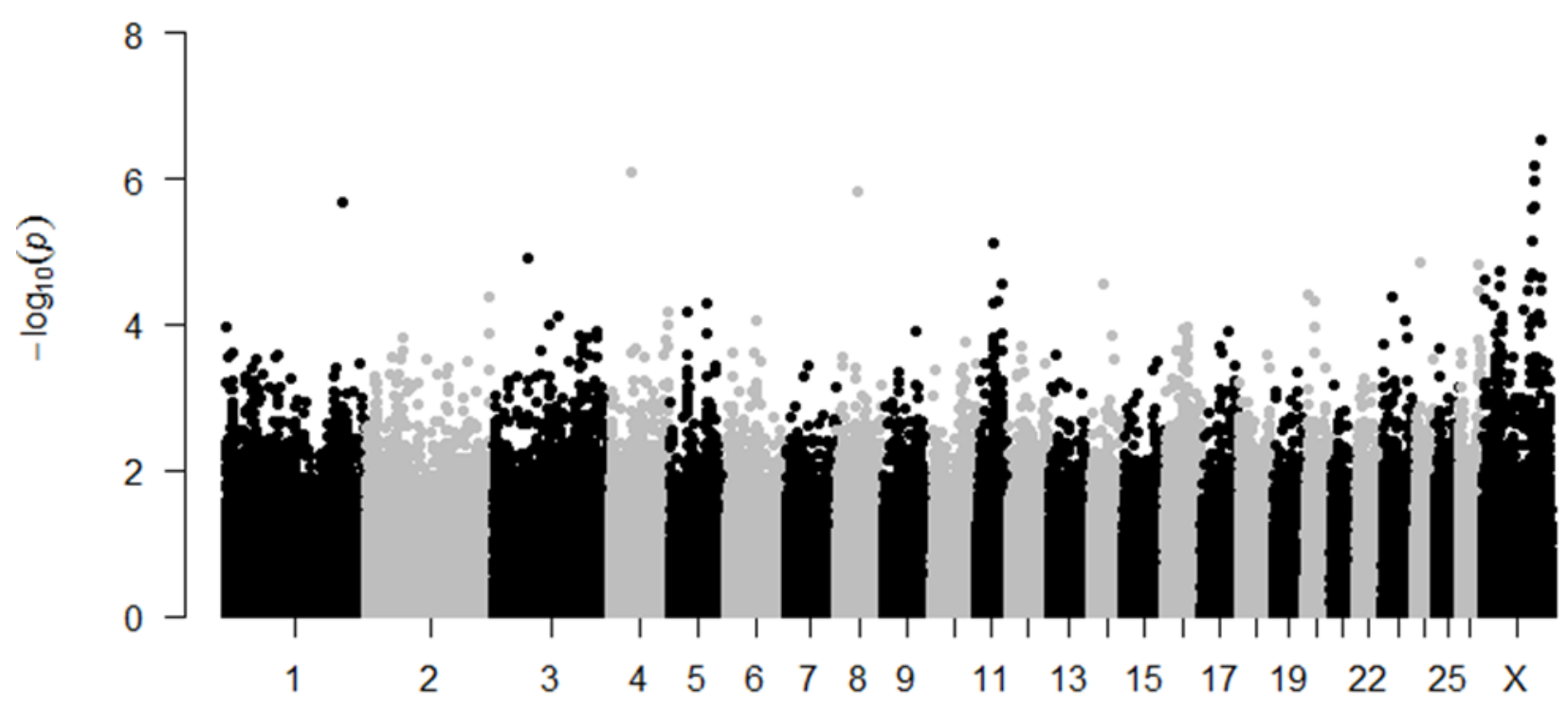

Chromosome

Figure 3 Manhattan plot of results from Fisher's exact for association of SNP genotype with wet carcass syndrome based on 69 samples from both males and females. The physical position of the SNP according to chromosome number is plotted on the x-axis, while the -log10P-values are plotted on the $y$-axis 


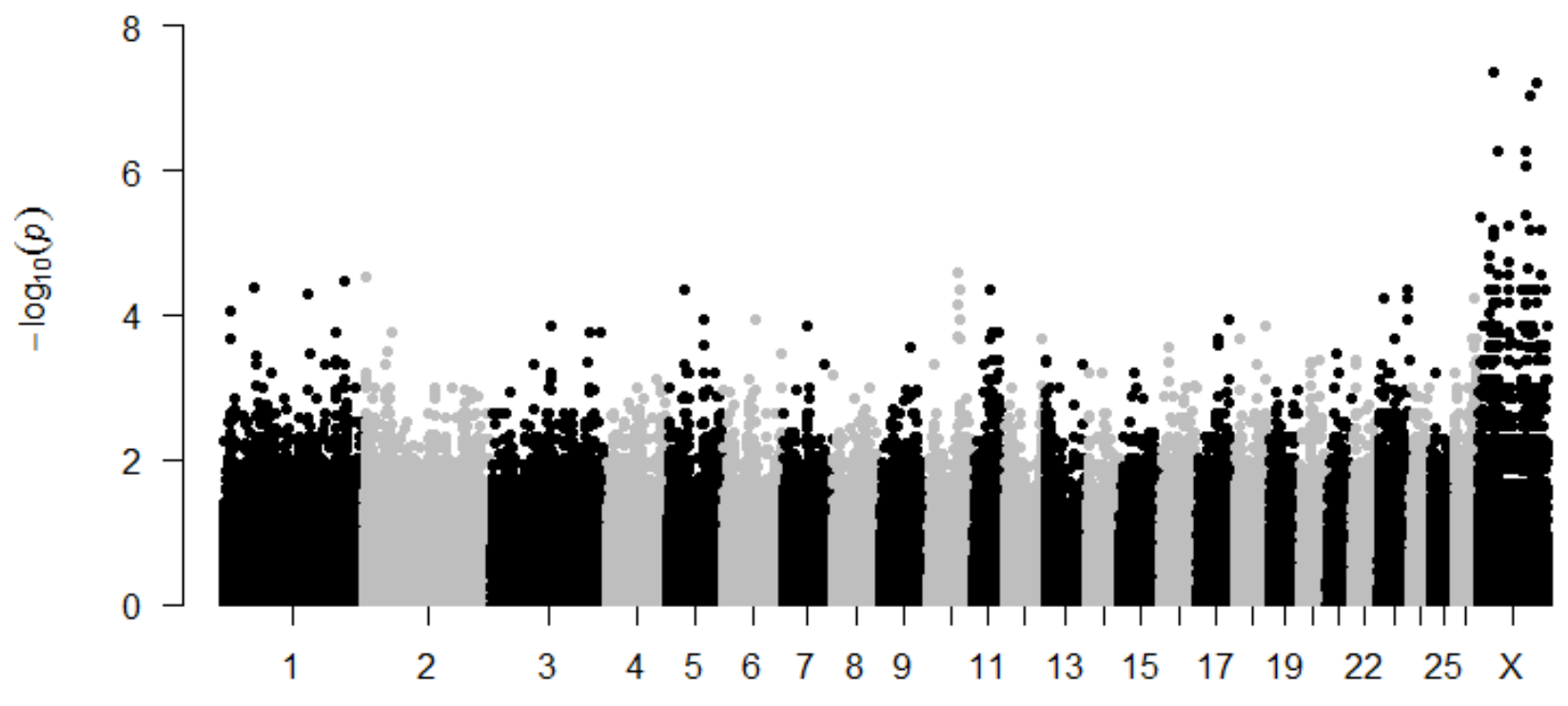

Chromosome

Figure 4 Manhattan plot of results from Fisher's exact test for association of SNP genotype with wet carcass syndrome based on samples from only the 38 males. The physical position of the SNP according to chromosome number is plotted on the $x$-axis, while the -log10P-values are plotted on the $y$-axis

Without discounting possible sex dimorphism in the effects of variants (Dobyns et al., 2004), the strong evidence for an association between hemizygous alleles and WCS in males and the lack of even suggestive evidence of a similar association in females may be explained by the possible co-expression of heterozygous genotypes at autosomal loci, because random X-inactivation results in a mixture of cells in different tissues (Taylor, 2014). An imbalance of the $X$ chromosomes between males (XY) and females (XX) and in the absence of $X$-inactivation, genes on OARX would be over-expressed in females relative to males. However, this imbalance is resolved by random inactivation of one of the $X$ chromosomes in each of the somatic cells (Lyon, 2001). This dosage compensation results in the expression of only one allele of most genes in the non-homologous region of $X$ in females.

Findings from this study that are potentially related the differences observed between males and females include i) afflicted and unafflicted females in approximately equal numbers carried the 'associated' genotypes at oar3_OARX_29903534 and oar3_OARX_113973214, thus providing a plausible reason for the lack of apparent association found in the GWAS analysis of females; ii) all afflicted animals had a 'G' allele for marker oar3_OARX_113973214, which had a significant influence on the WCS phenotype; iii) 20 unafflicted animals also carried the 'G' allele of oar3_OARX_113973214; and iv) some females, both afflicted and unafflicted, were heterozygous for oar3_OARX_113973214. Given the apparent influence of stress on phenotypically similar conditions in other species, it was speculated that these unafflicted males and females that carried this specific allele might not have experienced adequate levels of stress to manifest the WCS condition post slaughter. This ambiguity may be the result of incomplete penetrance (Zlotogora, 2003; Shawky, 2014). Incomplete penetrance affecting the expression of PSS has previously been observed in pigs (Ollivier et al., 1975; Smith \& Bampton, 1978). In humans, penetrance in expression of the afflicted condition resulting from mutations in RYR1 was significantly greater in males than in females (50\% versus $30 \% ; P=0.002$ ), despite similar levels of exposure to trigger anaesthetics (Ibarra Moreno et al., 2019).

Marker oar3_OARX_29903534 is located within the DMD gene. The DMD gene is X-linked, encodes the dystrophin protein (Hoffman et al., 1987; Koenig et al., 1988), and is the leading cause of DMD in young boys (Moser et al., 1984; Allen \& Whitehead, 2011). Increased plasma creatine phospho kinase (CPK) levels and dilated cardiomyopathy have been observed in DMD patients (Kirchmann et al., 2005; Magri et al., 2011). Allen \& Whitehead (2011) proposed that increased CPK levels are indicative of an increase in the permeability of the muscle surface membrane, which allows for calcium ions to move into the intracellular region and enzymes to move out. However, the exact cause of the muscle permeability is unclear. Nonneman et al. (2012) found that a variant of the DMD gene caused a novel porcine stress syndrome. Nonneman et al. (2012) then showed that this condition could be induced by handling, transport and isoflurane anaesthesia. 
Non-ambulatory response and fatigue, coupled with the classical symptoms of acute stress and sensitivity to halothane anaesthesia, have been observed in pigs and are similar to the symptoms exhibited by animals that carry a mutated ryanodine receptor 1 (RYR1) gene (Fujii et al., 1991; Allison et al., 2005). Moreover, animals that are affected by mutations in the $D M D$ gene showed reduced dystrophin protein in the skeletal and heart muscles, and in increased CPK levels (Nonneman et al., 2012). With WCS carcasses, if there is a causal mutation in the DMD gene, the phenotype could be because of an increase in permeability of the cell membranes of muscles, which causes the typical shiny wet appearance of WCS. Similarly, if one assumes that the genetic predisposition of WCS exists as a causal mutation in the DMD gene, a hypothetical mechanism by which the DMD gene may cause WCS is through an increase in cell membrane permeability. An increase in cell membrane permeability by influencing the water-holding capacity of muscles may play a major role.

Marker oar3_OARX_113973214 was found to be in an intergenic region, positioned roughly $6 \mathrm{kbp}$ downstream of the position the 5-hydroxytryptamine (serotonin) receptor 2C (LOC101108550 or HTR2C) gene. Two functions of the HTR2C gene are potentially relevant to WCS given its physiological characteristics. These functions included stress responsiveness and calcium ion homeostasis. Stress may influence the manifestation of WCS in sheep (Jansen \& Pretorius, 1986; Jansen, 1991) similar to the relationship between stress and PSS in pigs (Hall et al., 1980; MacLennan \& Phillips, 1992). Mutations in the RYR1 gene cause the calcium release channel to function improperly in afflicted pigs and poultry, resulting in the production of PSE meat under stressful conditions (Paião et al., 2013; Fisher et al., 2000). There is little doubt that there is a phenotypic similarity between PSS and WCS (Van der Westhuizen, 2018). Therefore, the HTR2C gene and its product the $5-\mathrm{HT} 2 \mathrm{C}$ receptor may disrupt the calcium ion homeostasis of WCS carcasses, and therefore result in a phenotypically similar carcass to PSE. Thus, these two genes RYR1 (in pigs) and HTR2C (in sheep) may either act independently of each other or may be part of the same gene network that is functionally related to cause a similar phenotype in different species. It is well established that the 5-HT2C receptors are involved in stress response in humans (Miller \& O'Callaghan, 2002; Donovan \& Tecott, 2013; Avery \& Vrshek-Schallhorn, 2016) and in anxiety (Griebel, 1995; Heisler et al., 2007a). Additionally, 5-HT2C receptors are involved in processes such as the coordination of the intracellular responses to serotonin, specifically in the central nervous system of mammalian species, homeostatic and behavioural responses, stress response, sexual behaviour, appetite control, obesity, and feeding behaviour in mice (Tecott et al., 1995; Nonogaki et al., 2003). Two wholly hypothetical mechanisms that may result in the manifestation of WCS (Quilter et al., 2012) are summarized here.. First, genetic inactivation or malfunctioning of the $5-\mathrm{HT} 2 \mathrm{C}$ receptor disrupts the regulation of the hypothalamic-pituitary-adrenal axis through serotonin (Heisler et al., 2007b). This disruption causes the live animal to respond ineffectively to stress, whether it is long term on the farm or acute pre-slaughter, and as a final consequence to manifest WCS post slaughter. Second, the normal biochemical process of muscle contraction that is initialized by serotonin binding to the receptor and ending with the continuing release of calcium ions from the sarcoplasmic reticulum to the cytoplasm of the cells is disrupted with the end result being the reduced waterholding capacity of the meat. Assuming the genetic predisposition of WCS exists as a causal mutation within the HTR2C gene, a disruption in cell homeostasis may occur, either during the pre-slaughter period of sheep by means of stress and anxiety or during the post-slaughter period through the calcium ion homeostasis mechanism within the cells of affected muscles.

\section{Conclusions}

The results attest to a potential genetic basis for WCS and its putative association with oar3_OARX_29903534 and oar3_OARX_113973214. Given the physical proximity of these loci with the $D M D$ and $H \bar{T} R 2 C$ genes and the effects of these genes in other species, they are suggested as positional and functional candidate genes for WCS in sheep. The numbers for the current study would have been adequate, based on the original hypothesis that the genetic basis for WCS was caused by a simple autosomal recessive allele. Since this is probably not the case, and the mechanism seems to be more complex, involving the $\mathrm{X}$ chromosome, more samples are needed. The inconclusiveness of the genetic findings here leads to the suggestion that future studies should conclusively establish a genetic basis for WCS. Progression toward developing a genetic test to identify animals that are genetically predisposed to WCS is warranted only once this genetic basis is verified.

\section{Acknowledgements}

The authors thank the International Sheep Genomics Consortium (ISGC), in conjunction with FarmIQ for the use of the Ovine Infinium ${ }^{\circledR}$ HD SNP BeadChip. Red Meat Research and Development SA (RMRD SA), Technology for Human Resources for Industry Programme (THRIP), ARC-Animal Production and National Research Foundation (NRF) of South Africa provided much needed financial support. The ARC-Biotechnology Platform (ARC-BTP) provided facilities 
and the authors particularly acknowledge Ms S. Cornelissen and Mr A. Ngobeni for their technical assistance during the genotyping process. They also thank the staff at the abattoirs of De Aar (samples were collected, but not processed), Groblershoop, Upington and Mariental for their assistance throughout the sampling process. Finally, the authors would like to thank Ms M. le Roux from Department of Agriculture, Land Reform \& Rural Development in the Northern Cape, South Africa, for the initial discussion and problem identification on WCS and Prof Edward Webb from the University of Pretoria, who assisted with the development of the research proposal and shared his knowledge of WSC.

\section{Author's Contributions}

LW carried out the research and developed the initial manuscript. MDM and MMS formulated the original hypothesis that lead to the investigation. MDM provided research direction, assisted in the interpretation of the results, and assisted in finalizing the manuscript. MMS obtained funding to support the research, supervised LW in its conduct, and assisted in finalizing the manuscript. FWCN provided academic supervision for LW, and assisted in interpreting the results and in finalizing the manuscript.

\section{Conflict of Interest Declaration}

The authors declare that there are no conflicts of interest.

\section{References}

Aalhus, J.L., Best, D.R., Murray, A.C. \& Jones, S.D.M., 1998. A comparison of the quality characteristics of pale, soft and exudative beef and pork. J. Muscle Foods 9, 267-280.

Adzitey, F. \& Nurul, L., 2011. Pale soft exudative (PSE) and dark firm dry (DFD) meats: Causes and measures to reduce these incidences - A mini review. Int. Food. Res. J. 18, 11-20.

Aken, B.L., Ayling, S., Barrell, D., Clarke, L., Curwen, V., ..., Searle, S.M.J., 2016. The Ensembl gene annotation system. Database 2016, baw093. doi: 10.1093/database/baw093.

Allen, D.G. \& Whitehead, N.P., 2011. Duchenne muscular dystrophy - what causes the increased membrane permeability in skeletal muscle? Int. J. Biochem. Cell. Biol. 43, $290-294$. https://doi.org/10.1016/j.biocel.2010.11.005.

Allison, C.P., Johnson, R.C. \& Doumit, M.E., 2005. The effects of halothane sensitivity on carcass composition and meat quality in HAL-1843-normal pigs. J. Anim. Sci. 83, 671-678.

Al-Mamun, H.A., Kwan, P., Clark, S.A., Ferdosi, M.H., Tellam, R. \& Gondro, C., 2015. Genome-wide association study of body weight in Australian Merino sheep reveals an orthologous region on OAR6 to human and bovine genomic regions affecting height and weight. Genet. Sel. Evol. 47, 66. https://doi.org/10.1186/s12711-015-0142-4.

Alonso, N., Lucas, G. \& HYSI, P., 2015. Big data challenges in bone research: Genome-wide association studies and next-generation sequencing. BoneKEy Reports 4, 635.

Altschul, S.F., Madden, T.L., Schäffer, A.A., Zhang, J, Zhang, Z., Miller, W. \& Lipman, D.J., 1997. Gapped BLAST and PSI-BLAST: A new generation of protein database search programs. Nucleic Acids Res. 25, 3389-3402.

Anderson, C.A., Pettersson, F.H., Clarke, G.M., Cardon, L.R., Morris, A.P. \& Zondervan, K.T., 2010. Data quality control in genetic case-control association studies. Nature Protocols 5, 1564-1573.

Avery, B.M. \& Vrshek-Schallhorn, S., 2016. Nonsynonymous HTR2C polymorphism predicts cortisol response to psychosocial stress I: Effects in males and females. Psychoneuroendocrinology 70, $134-141$. https://doi.org/10.1016/j.psyneuen.2015.12.023.

Balding, D.J., 2006. A tutorial on statistical methods for population association studies. Nat. Rev. Genet. 7, $781-791$. https://doi.org/10.1038/nrg1916.

Brock, R.M., Joubert, J.P.J., Hattingh, A., Mitchell, G., Newsholme, S.J., Van der Veen, R.R., Hofmeyr, H.S., Engels, E.A.N., Groenewald, H.B. \& Hunter, P., 1983. Ovine wet carcass syndrome unknown aetiology. S. Afr. J. Anim. Sci. 13, 194-195.

Cardon, L.R. \& Palmer, L.J., 2003. Population stratification and spurious allelic association. Lancet 361, 598-604. https://doi.org/10.1016/S0140-6736(03)12520-2.

Chen, J.F., Dai, L.H., Peng, J., Li, J.L., Zheng, R., Zuo, B., Li, F.E., Liu, M., Yue, K., Lei, M.G., Xiong, Y.Z., Deng, C.Y. \& Jiang, S.W., 2008. New evidence of alleles (V199I and G52S) at the PRKAG3 (RN) locus affecting pork meat quality. Asian-Australas. J. Anim. Sci. 21, 471-477.

Ciobanu, D., Bastiaansen, J., Malek, M., Helm, J., Woollard, J., Plastow, G. \& Rothschild, M., 2001. Evidence for new alleles in the protein kinase adenosine monophosphate activated $ү 3$-subunit gene associated with low glycogen content in pig skeletal muscle and improved meat quality. Genetics 159, 1151-1162.

Clarke, G.M., Anderson, C.A., Pettersson, F.H., Cardon, L.R., Morris, A.P. \& Zondervan, K.T., 2011. Basic statistical analysis in genetic case-control studies. Nat. Protoc. 6, 121-133. https://doi.org/10.1038/nprot.2010.182.

Das, P., Chowdhary, B.P. \& Raudsepp, T., 2009. Characterization of the bovine pseudoautosomal region and comparison with sheep, goat, and other mammalian pseudoautosomal regions. Cytogenet. Genome Res. 126, 139-147.

Demars, J., Fabre, S., Sarry, J., Rossetti, R., Gilbert, H., ..., Bodin, L., 2013. Genome-wide association studies identify two novel BMP15 mutations responsible for an atypical hyperprolificacy phenotype in sheep. PLoS Genet. 9, e1003482. https://doi.org/10.1371/journal.pgen.1003482.

Dobyns, W.B., Filauro, A., Tomson, B.N., Chan, A.S., Ho, A.W., Ting, N.T., Oosterwijk, J.C. \& Ober, C., 2004 Inheritance of most X-linked traits is not dominant or recessive, just X-linked. Am. J. Med. Genet. A. 129A, 136143. 
Donovan, M.H. \& Tecott, L.H., 2013. Serotonin and the regulation of mammalian energy balance. Front. Neurosci. 7,36 https://doi.org/10.3389/fnins.2013.00036.

Endo, M., Yagi, S., Ishizuka, T., Horiuti, K., Koga, Y. \& Amaha, K., 1983. Changes in the Ca-induced Ca release mechanism in the sarcoplasmic reticulum of muscle from patient with malignant hyperthermia. Biomed. Res. 4, 83-92.

Enfält, A.C., Lundström, K., Hansson, I., Johansen, S. \& Nyström, P.-E., 1997. Comparison of non-carriers and heterozygous carriers of the RN- allele for carcass composition, muscle distribution and technological meat quality in Hampshire-sired pigs. Livest. Prod. Sci. 47, 221-229.

Fill, M., Coronado, R., Mickelson, J.R., Vilven, J., Ma, J.J., Jacobson, B.A. \& Louis, C.F., 1990. Abnormal ryanodine receptor channels in malignant hyperthermia. Biophys. J. 50, 471-475.

Fisher, P., Mellett, F.D. \& Hoffman, L.C., 2000. Halothane genotype and pork quality. 1. Carcass and meat quality characteristics of three halothane genotypes. Meat Sci. 54, 97-105.

Fujii, J., Otsu, K., Zorzato, F., de Leon, S., Khanna, V.K., Weiler, J.E., O'Brien, P.J. \& MacLennan, D.H., 1991. Identification of a mutation in porcine ryanodine receptor associated with malignant hyperthermia. Science 253 , 448-451.

García-Gámez, E., Gutiérrez-Gil, B., Sahana, G., Sánchez, J-P., Bayón, Y. \& Arranz, J-J., 2012. GWA analysis for milk production traits in dairy sheep and genetic support for a QTN influencing milk protein percentage in the LALBA gene. PLoS ONE 7, e47782. https://dx.doi.org/10.1371/journal.pone.0047782.

Greyvenstein, O.F.C., Reich, C.M., Van Marle-Koster, E., Riley, D.G. \& Hayes, B.J., 2016. Polyceraty (multi-horns) in Damara sheep maps to ovine chromosome 2. Anim. Genet. 47, 263-266. https://doi.org/10.1111/age.12411.

Gottipati, S., Arbiza, L., Siepel, A., Clark, A.G. \& Keinan, A., 2011. Analyses of X-linked and autosomal genetic variation in population-scale whole genome sequencing. Nature Genetics 43, 741-743.

Griebel, G., 1995. 5-Hydroxytryptamine-interacting drugs in animal models of anxiety disorders: More than 30 years of research. Pharmacol. Ther. 65, 319-395. doi.org/10.1016/0163-7258(95)98597-J.

Hall, G.M., Lucke, J.N. \& Lister, D., 1980. Malignant hyperthermia - Pearls out of swine. Br. J. Anaesth. 52, 165-171.

Hao, X., Plastow, G., Zhang, C., Xu, S., Hu, Z., ..., Zhang, S., 2017. Genome-wide association study identifies candidate genes for piglet splay leg syndrome in different populations. BMC Genet. 18, 64. doi.org/10.1186/s12863-0170532-4.

Harbitz, I., Chowdhary, B., Thomsen, P.D., Davies, W., Kaufmann, U., Kran, S., Gustavsson, I., Christensen, K. \& Hauge, J.G., 1990. Assignment of the porcine calcium release channel gene, a candidate for the malignant hyperthermia locus, to the 6p11-q21 segment of chromosome 6 . Genomics 8, 243-248.

Harhay, G.P. \& Keele, J.W., 2003. Positional candidate gene selection from livestock EST databases using gene ontology. Bioinformatics 19, 249-255. Doi: 10.1093/bioinformatics/19.2.249.

Hattingh, J., Mitchell, G. \& Ganhao, M.F., 1983. The composition of plasma and interstitial fluid of sheep with the 'wet carcass' syndrome. J. S. Afr. Vet. Assoc. 54, 87-89.

Heisler, L.K., Pronchuk, N., Nonogaki, K., Zhou, L., Raber, J., ..., Tecott, L.H., 2007a. Serotonin activates the hypothalamic-pituitary-adrenal axis via serotonin 2C receptor stimulation. J. Neurosci. 27, 6956-6964. doi.org/10.1523/jneurosci.2584-06.2007.

Heisler, L., Zhou, L., Bajwa, P., Hsu, J. \& Tecott, L., 2007b. Serotonin 5-HT(2C) receptors regulate anxiety-like behavior. Genes Brain Behav. 6, 491-496. Doi.org/10.1111/j.1601-183x.2007.00316.x.

Hirschhorn, J.N., Lohmueller, K., Byrne, E. \& Hirschhorn, K., 2002. A comprehensive review of genetic association studies. Genet. Med. 4, 45-61.

Hirschhorn, J.N. \& Daly, M.J., 2005. Genome-wide association studies for common diseases and complex traits. Nat. Rev. Genet. 6, 95-108. https://doi.org/10.1038/nrg1521.

Hoffman, E.P., Brown, R.H. \& Kunkel, L.M., 1987. Dystrophin: The protein product of the Duchenne muscular dystrophy locus. Cell 51, 919-928. https://doi.org/10.1016/0092-8674(87)90579-4.

Ibarra Moreno, C.A., Hu S., Kraeva N., Schuster F., Johannsen S., Rueffert H., Klingler W., Heytens L. \& Riazi S. 2019. An assessment of penetrance and clinical expression of malignant hyperthermia in individuals carrying diagnostic Ryanodine Receptor 1 gene mutations. Anesthesiology doi: 10.1097/ALN.0000000000002813.

Jansen, B.N., 1991. 'n Ondersoek na die moontlike oorsaaklike fisiografies, fisiochemiese en/of anatomies-patologiese faktore van natkarkassindroom by skape. PhD thesis, University of the Free State, South Africa (in Afrikaans).

Jansen, B.N. \& Pretorius, P.S., 1986. Wet carcass syndrome in sheep: Incidence and geographical distribution. J. S. Afr. Vet. Assoc. 57, 25-27.

Johnston, S.E., McEwan, J.C., Pickering, N.K., Kijas, J.W., Beraldi, D., Pilkington, J.G., Pemberton, J.M. \& Slate, J., 2011. Genome-wide association mapping identifies the genetic basis of discrete and quantitative variation in sexual weaponry in a wild sheep population. Mol. Ecol. 20, 2555-2566. https://doi.org/10.1111/j.1365294X.2011.05076.x.

Joubert, J.P.J., Marais, P.G. \& Smith, F.J.C., 1985. Ovine wet carcass syndrome induced by water deprivation and subsequent over-hydration: Preliminary findings. J. S. Afr. Vet. Assoc. 56, 17-19.

Kemper, K.E., Visscher, P.M. \& Goddard, M.E., 2012. Genetic architecture of body size in mammals. Genome. Biol. 13, 244. https://doi.org/10.1186/gb-2012-13-4-244.

Kijas, J.W., Porto-Neto, L., Dominik, S., Reverter, A., Bunch, R..., ..., International Sheep Genomics Consortium, 2014. Linkage disequilibrium over short physical distances measured in sheep using a high-density SNP chip. Anim. Genet. 45, 754-757. https://doi.org/10.1111/age.12197.

Kim, H.-Y., 2017. Statistical notes for clinical researchers: Chi-squared test and Fisher's exact test. Restor. Dent. Endod. 42, 152-155. doi:10.5395/rde.2017.42.2.152. 
Kirchmann, C., Kececioglu, D., Korinthenberg, R. \& Dittrich, S., 2005. Echocardiographic and electrocardiographic findings of cardiomyopathy in Duchenne and Becker-Kiener muscular dystrophies. Pediatr. Cardiol. 26, 66-72 https://doi.org/10.1007/s00246-004-0689-2.

Koenig, M., Monaco, A.P. \& Kunkel, L.M., 1988. The complete sequence of dystrophin predicts a rod-shaped cytoskeletal protein. Cell 53, 219-228. https://doi.org/10.1016/0092-8674(88)90383-2.

Kominakis, A., Hager-Theodorides, A.L., Zoidis, E., Saridaki, A., Antonakos, G. \& Tsiamis, G., 2017. Combined GWAS and 'guilt by association'-based prioritization analysis identifies functional candidate genes for body size in sheep. Genet. Sel. Evol. 49, 41. https://doi.org/10.1186/s12711-017-0316-3.

Le Roux, M., 2012. Provisional report for the 'wet carcass syndrome trial' conducted at the Karakul Research station, Upington. Department of Agriculture, Land Reform and Rural Development, Northern Cape, South Africa.

Le Roy, P., Naveau, J., Elsen, J.M. \& Sellier, P., 1990. Evidence for a new major gene influencing meat quality in pigs. Genet. Res. 55, 33-40.

Le Roy, P., Juin, H., Caritez, J.C., Billon, Y., Lagant, H., Elsen, J.M. \& Sellier, P., 1996. Effet du génotype RN sur les qualités sensorielles de la viande de porc. Journ. Rech. Porc. France. 28, 53-56 (in French).

Lindahl, G., Enfält, A.-C., Von Seth, G., Josell, Å., Hedebro-Velander, I., Andersen, H.J., Braunschweig, M., Andersson, L. \& Lundström, K., 2004. A second mutant allele (V199I) at the PRKAG3 (RN) locus - I. Effect on technological meat quality of pork loin. Meat Sci. 66, 609-619.

Ludvigsen, J., 1957. On the hormonal regulation of vasomotor reactions during exercise with special reference to the action of adrenal cortical steroids. Acta. Endocrinol. 26, 406-416.

Lundström, K., Andersson, A. \& Hansson, I., 1996. Effect of the RN gene on technological and sensory meat quality in crossbred pigs with Hampshire as terminal sire. Meat Sci. 42, 145-153.

Lyon, M.F. 2001. X-Chromosome Inactivation. In: Sydney Brenner and Jefferey H. Miller (ed.) Encyclopedia of Genetics, 1st edtion. Academic Press, Amsterdam. pp 2148-2149.

MacLennan, D.H. \& Phillips, M.S., 1992. Malignant hyperthermia. Science 256, 789-794.

Magri, F., Del Bo, R., D'Angelo, M.G., Govoni, A., Ghezzi, S., .., Comi, G.P., 2011. Clinical and molecular characterization of a cohort of patients with novel nucleotide alterations of the Dystrophin gene detected by direct sequencing. BMC Med. Genet. 12, 37.

Mariani, P., Lundström, K., Gustafsson, U., Enfält, A.-C., Juneja, R.K. \& Andersson, L., 1996. A major locus (RN) affecting muscle glycogen content is located on pig chromosome 15. Mamm. Genome. 7, 52-54.

McCurdy, R.D., Barbut, S. \& Quinton, M., 1996. Seasonal effect on pale soft exudative (PSE) occurrence in young turkey breast meat. Food Res. Int. 29, 363-366.

McKee, S.R., Hargis, B.M. \& Sams, A.R., 1998. Pale, soft and exudative meat in turkeys treated with succinylcholine. Poult. Sci. 77, 356-360.

Milan, D., Le Roy, P., Woloszyn, N., Caritez, J.C., Elsen, J.M., Sellier, P. \& Gellin, J., 1995. The RN locus for meat quality maps to pig chromosome 15. Genet. Sel. Evol. 27, 195-199.

Milan, D., Jeon, J.-T., Looft, C., Amarger, V., Robic, A., ..., Andersson, L., 2000. A mutation in PRKAG3 Associated with excess glycogen content in pig skeletal muscle. Science 288, 1248.

Miller, D.B. \& O'Callaghan, J.P., 2002. Neuroendocrine aspects of the response to stress. Metabolism 51, 5-10. https://doi.org/10.1053/meta.2002.33184

Miller, K.D., Ellis, M., Bidner, B., McKeith, F.K. \& Wilson, E.R., 2000. Porcine Longissimus glycolytic potential level effects on growth performance, carcass, and meat quality characteristics. J. Muscle Foods. 11, 169-181.

Miyagawa, T., Nishida, N., Ohashi, J., Kimura, R., Fujimoto, A., ..., Tokunaga, K., 2008. Appropriate data cleaning methods for genome-wide association study. J. Hum. Genet. 53, 886-893 https://doi.org/10.1007/s10038-0080322-y.

Moser, H. 1984. Duchenne muscular dystrophy: Pathogenetic aspects and genetic prevention. Hum. Genet. 66,17-40.

Nonneman, D.J., Brown-Brandl, T., Jones, S.A., Wiedmann, R.T. \& Rohrer, G.A., 2012. A defect in dystrophin causes a novel porcine stress syndrome. BMC Genomics 13, 233. https://doi.org/10.1186/1471-2164-13-233.

Nonogaki, K., Abdallah, L., Goulding, E.H., Bonasera, S.J. \& Tecott, L.H., 2003. Hyperactivity and reduced energy cost of physical activity in serotonin 5- $\mathrm{HT}_{2 \mathrm{C}}$ receptor mutant mice. Diabetes 52, 315-320. https://doi.org/10.2337/diabetes.52.2.315.

O'Brien, P.J., 1986. Porcine malignant hyperthermia susceptibility: Hypersensitive calcium-release mechanism of skeletal muscle sarcoplasmic reticulum. Can. J. Vet. Res. 50, 318-328.

Ollivier, L., Sellier, P., Monin, G. 1975. Déterminisme génétique du syndrome d'hyperthermie maligne chez le porc de Piétrain. Annales de Génétique et de Sélection animale 7,159-166. (In French).

Owens, C.M., Hirschler, E.M., McKee, S.R., Martinez-Dawson, R. \& Sams, A.R., 2000. The characterization and incidence of pale, soft, exudative turkey meat in a commercial plant. Poult. Sci. 79, 553-558.

Paião, F.G., Ferracin L.M., Pedrão, M., Kato, T. \& Shimokomaki, M., 2013. Skeletal muscle calcium channel ryanodine and the development of pale, soft, and exudative meat in poultry. Genet. Mol. Res. 12, 3017-3027.

Purcell, S., Neale, B., Todd-Brown, K., Thomas, L., Ferreira, M.A.R., ..., Sham, P.C., 2007. PLINK: A tool set for wholegenome association and population-based linkage analyses. Am. J. Hum. Genet. 81, 559-575.

Quilter, C.R., Bagga, M., Moinie, A., Junaid, F. \& Sargent, C.A., 2012. Gene structure and expression of serotonin receptor HTR2C in hypothalamic samples from infanticidal and control sows. BMC Neurosci. $13,37$. https://doi.org/10.1186/1471-2202-13-37.

R Core Team., 2013. R: A language and environment for statistical computing. R Foundation for Statistical Computing, Vienna, Austria. http://www.R-project.org/. 
Sayers, E.W., Agarwala, R., Bolton, E.E., Brister, J.R., Canese, K., .., Ostell, J., 2019a. Database resources of the National Center for Biotechnology Information. Nucleic Acids Res. 47(D1), D23-D28. doi: 10.1093/nar/gky1069.

Sayers, E.W., Cavanaugh, M., Clark, K., Ostell, J., Pruitt, K.D. \& Karsch-Mizrachi I., 2019b. GenBank. Nucleic Acids Res. 47(D1), D94-D99. doi: 10.1093/nar/gky989.

Schaefer, A.L., Dubeski, P.L., Aalhus, J.L. \& Tong, A.K.W., 2001. Role of nutrition on reducing antemortem stress and meat quality aberrations. J. Anim. Sci. 79, E91-E101.

Shawky, R.M., 2014. Reduced penetrance in human inherited disease. Egyptian J. Med. Hum. Genet. 15, $103-111$.

Škrlep, M., Kavar, T. \& Čandek-Potokar, M., 2010. Comparison of PRKAG3 and RYR1 gene effect on carcass traits and meat quality in Slovenian commercial pigs. Czech J. Anim. Sci. 55, 149-159.

Smith, C. \& Bampton, P.R., 1977. Inheritance of reaction to halothane anaesthesia in pigs. Genetical Res. 29:287-292.

Swatland, H.J., 2008. How pH causes paleness or darkness in chicken breast meat. Meat Sci. 80, 396-400.

Taylor, J.F., 2014. Implementation and accuracy of genomic selection. Aquaculture 420-421, S8-S14.,

Tecott, L.H., Sun, L.M., Akana, S.F., Strack, A.M., Lowenstein, D.H., Dallman, M.F. \& Julius, D., 1995. Eating disorder and epilepsy in mice lacking 5-HT2c serotonin receptors. Nature 374, 542-546.

Turner, S.D., 2014. qqman: An R package for visualizing GWAS results using Q-Q and Manhattan plots. https://doi.org/10.1101/005165.

Turner, S., Armstrong, L.L., Bradford, Y., Carlson, C.S., Crawford, D.C., ..., Ritchie, M.D., 2011. Quality control procedures for genome wide association studies. Curr. Protoc. Hum. Genet. Chapter 1, Unit1.19. https://doi.org/10.1002/0471142905.hg0119s68.

Van der Westhuizen, L., 2018. Identification of quantitative trait loci affecting wet carcass syndrome in sheep using high density SNP genotypes. PhD thesis, University of the Free State, South Africa.

Van Schalkwyk, S.J., Cloete, S.W.P., Hoffman, L.C., Brand, Z., Pfister, A.P. \& Punt, K., 2000. The effect of pre-slaughter stress resulting from feed withdrawal on meat quality characteristics in ostriches. S. Afr. J. Anim. Sci. 30, 147-148.

Wang, Z., Zhang, H., Yang, H., Wang, S., Rong, E., Pei, W., Li, H. \& Wang, N., 2014. Genome-wide association study for wool production traits in a Chinese merino sheep population. PLoS ONE 9, e107101. https://doi.org/10.1371/journal.pone.0107101.

Warner, R.D., Kauffman, R.G. \& Greaser, M.L., 1997. Muscle protein changes post mortem in relation to pork quality traits. Meat Sci. 45, 339-352.

Webb, E.C. \& Van Niekerk, W.A., 2011. Occurrence and aetiology of the 'wet carcass syndrome' in sheep in southern Africa. Proceedings of the 57th International Congress of Meat Science and Technology. Ghent, Belgium.

Wismer-Pedersen, J., 1959. Quality of pork in relation to rate of $\mathrm{pH}$ change post mortem. J. Food Sci. 24, 711-727.

Zhang, L., Liu, J., Zhao, F., Ren, H., Xu, L., ..., Du, L., 2013. Genome-wide association studies for growth and meat production traits in sheep. PLoS ONE 8, e66569. https://doi.org/10.1371/journal.pone.0066569.

Zhao, X., Dittmer, K.E., Blair, H.T., Thompson, K.G., Rothschild, M.F. \& Garrick, D.J., 2011. A novel nonsense mutation in the DMP1 gene identified by a genome-wide association study is responsible for inherited rickets in Corriedale sheep (GV Amdam, Ed.). PLoS ONE 6, e21739. https://doi.org/10.1371/journal.pone.0021739.

Zhao, X., Onteru, S., Rothschild, M.F. \& Garrick, D.J., 2012. Causative gene discovery for sheep inherited disorders. Iowa State University Animal Industry Report. https://lib.dr.iastate.edu/ans_air/vol657/iss1/49/.

Zheng, X., Levine, D., Shen, J., Gogarten, S.M., Laurie, C. \& Weir, B.S., 2012. A high-performance computing toolset for relatedness and principal component analysis of SNP data. Bioinformatics. 28, 3326-3328. https://doi.org/10.1093/bioinformatics/bts606.

Zlotogora, J., 2003. Penetrance and expressivity in the molecular age. Genet. Med. 5, 347-352. 